\title{
Malassezia: a case of coexisting pityriasis versicolor and Malassezia folliculitis
}

Singapore Med J 2020; 61(4): 221 https://doi.org/10.11622/smedj.2018079

Dear Sir,

In the human fungal biodata, Malassezia is the dominant species. It is a skin commensal that has been implicated in diseases such as pityriasis versicolor (PV), Malassezia folliculitis (MF), seborrhoeic dermatitis, atopic dermatitis and psoriasis. ${ }^{(1)}$ Environmental factors such as increased temperature, sweating, seborrhoea, (2) and immunosuppressive conditions such as human immunodeficiency virus (HIV) infections, diabetes mellitus and corticosteroid use are associated with a predisposition to the development of PV and MF. ${ }^{(3)}$

A 24-year-old Chinese man was referred to the dermatology clinic for an asymptomatic rash on his back, arms, thighs and buttocks of two months' duration. The patient had a past medical history of Evan's syndrome (autoimmune thrombocytopenia and haemolytic anaemia), for which he was on long-term azathioprine and prednisolone for immunosuppression. He was otherwise well and had no constitutional symptoms. On examination of the affected areas, there was a monomorphic erythematous pustular eruption with multiple annular scaly hypopigmented macules and patches within (Fig. 1). A fungal scrape from lesional areas was positive for hyphae and spores.

The diagnosis of concurrent PV and MF was made. Lifestyle modification with avoidance of humid conditions was advised. He was treated with topical miconazole cream and a threeweek course of oral ketoconazole $200 \mathrm{mg}$ twice daily. The rash improved marginally and he was given a further two-week course of oral ketoconazole. At that time, the haematologist also added cyclophosphamide to his immunosuppressive regime. After a total of five weeks of oral antifungals, his rash still failed to resolve. He was then prescribed itraconazole 200 mg every morning for one week, followed by 100 mg every morning for three weeks, which resulted in successful eradication of disease.

The various manifestations of Malassezia infections differ based on pathophysiology. For PV, lipase produced by Malassezia metabolises various fatty acids, producing metabolites (such as azelaic acid) that block the passage of tyrosine to melanin, resulting in hypopigmented macules. ${ }^{(2)}$ The predominant species is $\mathbf{M}$.

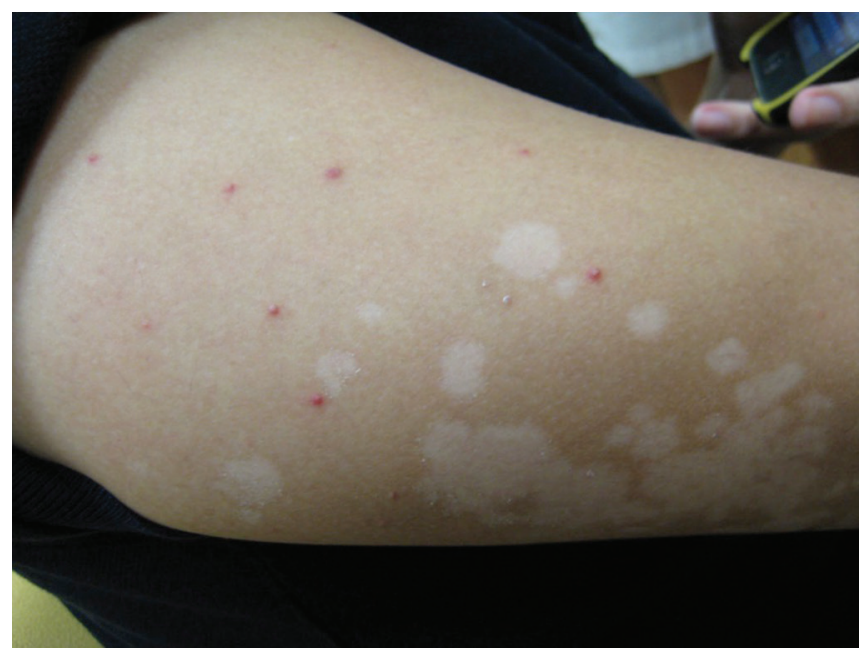

Fig. 1 Clinical photograph of the left arm shows erythematous monomorphic pustules interspersed with hypopigmented scaly macules and plaques. globosa. ${ }^{(4)}$ Microscopy shows the typical 'spaghetti and meatballs' appearance of both hyphae and spores, and this dimorphic appearance is unique to PV. ${ }^{(5)}$ There is an absence of an inflammatory infiltrate in histopathology. ${ }^{(6)}$ Conversely, MF is characterised by an inflammatory response to invasion of hair follicles and hydrolysis of triglycerides with yeast, resulting in erythematous papules or pustules. ${ }^{(1)}$ The predominant species involved are M. restricta, M. globosa and M. sympodialis. (1) Microscopically, only budding yeast cells are seen. ${ }^{(7)}$

The azole drugs, such as ketoconazole, itraconazole and voriconazole, have high in vitro antifungal efficacy in Malassezia species and are good options for systemic management of Malassezia infections, ${ }^{(8)}$ although a prolonged course may be necessary for clinical resolution, as illustrated in this case.

The presentation of both PV and MF in the same patient and at the same location highlights that two different pathological processes can occur simultaneously. The use of augmented immunosuppressive therapy may have predisposed the patient to dual manifestations of Malassezia infections.

Yours sincerely,

Ellie $\underline{\text { Choi }^{1}}$, Chris Lixian $\underline{\operatorname{Tan}}^{1}$, Derrick $\underline{\mathrm{Aw}}^{2}$

${ }^{1}$ Division of Dermatology, National University Hospital, 2Department of General Medicine, Sengkang General Hospital, Singapore. ellie_choi@nuhs.edu.sg

\section{References}

1. Harada K, Saito M, Sugita T, Tsuboi R. Malassezia species and their associated skin diseases. J Dermatol 2015; 42:250-7.

2. Mendez-Tovar LJ. Pathogenesis of dermatophytosis and tinea versicolor. Clin Dermatol 2010; 28:185-9.

3. Tragiannidis A, Bisping G, Koehler G, Groll AH. Minireview: Malassezia infections in immunocompromised patients. Mycoses 2010; 53:187-95

4. Crespo Erchiga V, Ojeda Martos A, Vera Casaño A, Crespo Erchiga A, Sanchez Fajardo F. Malassezia globosa as the causative agent of pityriasis versicolor. Br J Dermatol 2000; 143:799-803.

5. Gupta AK, Batra R, Bluhm R, Boekhout T, Dawson TL Jr. Skin diseases associated with Malassezia species. J Am Acad Dermatol 2004; 51:785-98.

6. Wroblewski N, Bär S, Mayser P. [Missing granulocytic infiltrate in pityriasis versicolor--indication of specific anti-inflammatory activity of the pathogen?] Mycoses 2005; 48 Suppl 1:66-71. German.

7. Ayers K, Sweeney SM, Wiss K. Pityrosporum folliculitis: diagnosis and management in 6 female adolescents with acne vulgaris. Arch Pediatr Adolesc Med 2005; $159: 64-7$.

8. Gupta AK, Kohli Y, Li A, Faergemann J, Summerbell RC. In vitro susceptibility of the seven Malassezia species to ketoconazole, voriconazole, itraconazole and terbinafine. Br J Dermatol 2000; 142:758-65. 